\title{
Abundance and seasonal distribution of the Southern North Carolina Estuarine System Stock of common bottlenose dolphins (Tursiops truncatus)
}

\author{
Dani Silva, Robert F. Young, Alyson Lavin, Cristina O’Shea and Emily Murray \\ Coastal Carolina University, Chanticler Drive E, Conway, SC 29528, USA \\ Contacte-mail:dcsilva@coastal.edu
}

\begin{abstract}
Under the US Marine Mammal Protection Act, common bottlenose dolphins along the United States Atlantic coast are managed as a series of 17 distinct stocks. To determine the status of each stock, the Potential Biological Removal (PBR) is compared with anthropogenic removals, primarily as a result of fisheries bycatch. Estimates of abundance, with associated measures of variance, are required to generate the PBR for each stock. The objectives of the current study were to estimate abundance for the Southern North Carolina Estuarine System Stock (SNCESS) of common bottlenose dolphins and to better define the southern boundary of this stock. To meet these objectives, photo-identification surveys were conducted during the summer and winter of 2014 in estuarine and nearshore coastal waters in southern North Carolina. The surveys extended $25 \mathrm{~km}$ South of the defined southern stock boundary, along the northern South Carolina coast. One mark and one recapture survey were conducted for each season. Each survey was completed in four or five days and covered over $300 \mathrm{~km}$ of survey tracklines. Dorsal fin images were processed and managed using FinBase, and only images of suitable quality and distinctiveness were used for estimates of abundance. A three-step decision tree was used to assign each dolphin group to either the SNCESS or an adjacent coastal stock, based on sighting location, ranging patterns derived from matches to photoidentification catalogues and statistical modelling. Only sightings classified as SNCESS were used to estimate stock abundance. Abundance estimates were calculated using three approaches: the Chapman modification to the Lincoln-Petersen method, package Rcapture in program R and program MARK 6.2. The most parsimonious approach was the Chapman LP method yielding an estimate of 272 dolphins (95\% CI $189-390$, CV $=0.32)$ in the summer of 2014. The distribution of SNCESS dolphins shifted South in the winter and several individuals were observed up to $70 \mathrm{~km}$ southwest of the currently recognised southern boundary. The results of this study support the current definition of the SNCESS but suggest revisions to the southern boundary. The SNCESS is the smallest bottlenose dolphin stock off the East coast of the USA and is at risk of population decline as a result of fisheries-related mortality.
\end{abstract}

KEYWORDS: ABUNDANCE ESTIMATE; COMMON BOTTLENOSE DOLPHIN; MARK-RECAPTURE; MODELLING; MOVEMENTS; NORTH AMERICA

\section{INTRODUCTION}

Common bottlenose dolphins (Tursiops truncatus) are managed as a complex mix of offshore, coastal and estuarine stocks along the US East coast. Under the Marine Mammal Protection Act (MMPA, 16 USC), these stocks require revisions and updated estimates of abundance and potential biological removal (PBR) at eight-year intervals (Wade and Angliss, 1997). The latest stock assessment reports (SARs) describe four overlapping bottlenose dolphin stocks off the state of North Carolina (USA): the Northern Migratory Coastal Stock (NM); the Southern Migratory Coastal Stock (SM); the Northern North Carolina Estuarine System Stock (NNCESS); and the Southern North Carolina Estuarine System Stock (SNCESS) (Waring et al., 2016). Estuarine and coastal migratory stocks overlap in nearshore coastal waters, complicating the collection of baseline data and the implementation of conservation and management plans. Estuarine stocks can be more vulnerable to localised anthropogenic impacts due to their limited range and smaller population size, thus knowledge of stock identity is particularly important in estuarine and nearshore coastal waters.

During summer months, the SNCESS reportedly ranges from a northern boundary in Core Sound/Southern Pamlico Sound, North Carolina (NC), to a southern boundary at Little River, South Carolina (SC) at the NC/SC border (Fig. 1; Waring et al., 2016). The northern boundary has been extensively studied and is described to shift South to approximately New River, North Carolina in the winter (Urian et al., 2014; Waring et al., 2016). The southern boundary has been defined largely based on the termination of the NC estuarine system at Little River Inlet, SC, to the South of which is a $90 \mathrm{~km}$ stretch of sandy beach coastline with no significant estuarine systems. The southern boundary is not reported to change seasonally but, unlike the northern boundary, no published surveys have focused on both sides of this boundary to confirm its location.

Read et al. (2003) provided the first abundance estimate for the SNCESS using mark-recapture photo-identification methods $(\tilde{\mathrm{N}}=141,95 \%$ CI $112-200, \mathrm{CV}=0.15)$. Urian et al. (2014) improved on Read et al.'s (2003) estimate by including coastal surveys up to $1 \mathrm{~km}$ from shore $(\tilde{\mathrm{N}}=188$, 95\% CI 118-257, CV $=0.19)$, but this estimate did not attempt to distinguish SNCESS dolphins from the coastal stock(s) along nearshore coastal waters. These previous estimates are similar; suggesting that population size for the SNCESS had not changed considerably. PBR for the SNCESS was estimated at 1.6 dolphins (Waring et al., 2016), suggesting an anthropogenic removal of two dolphins per year would be unsustainable. However, the estimated PBR from Urian et al. (2014) was based on surveys conducted in 2006 and is no longer considered valid because it is older than the accepted eight-year regulatory window (Wade and Angliss, 1997). 


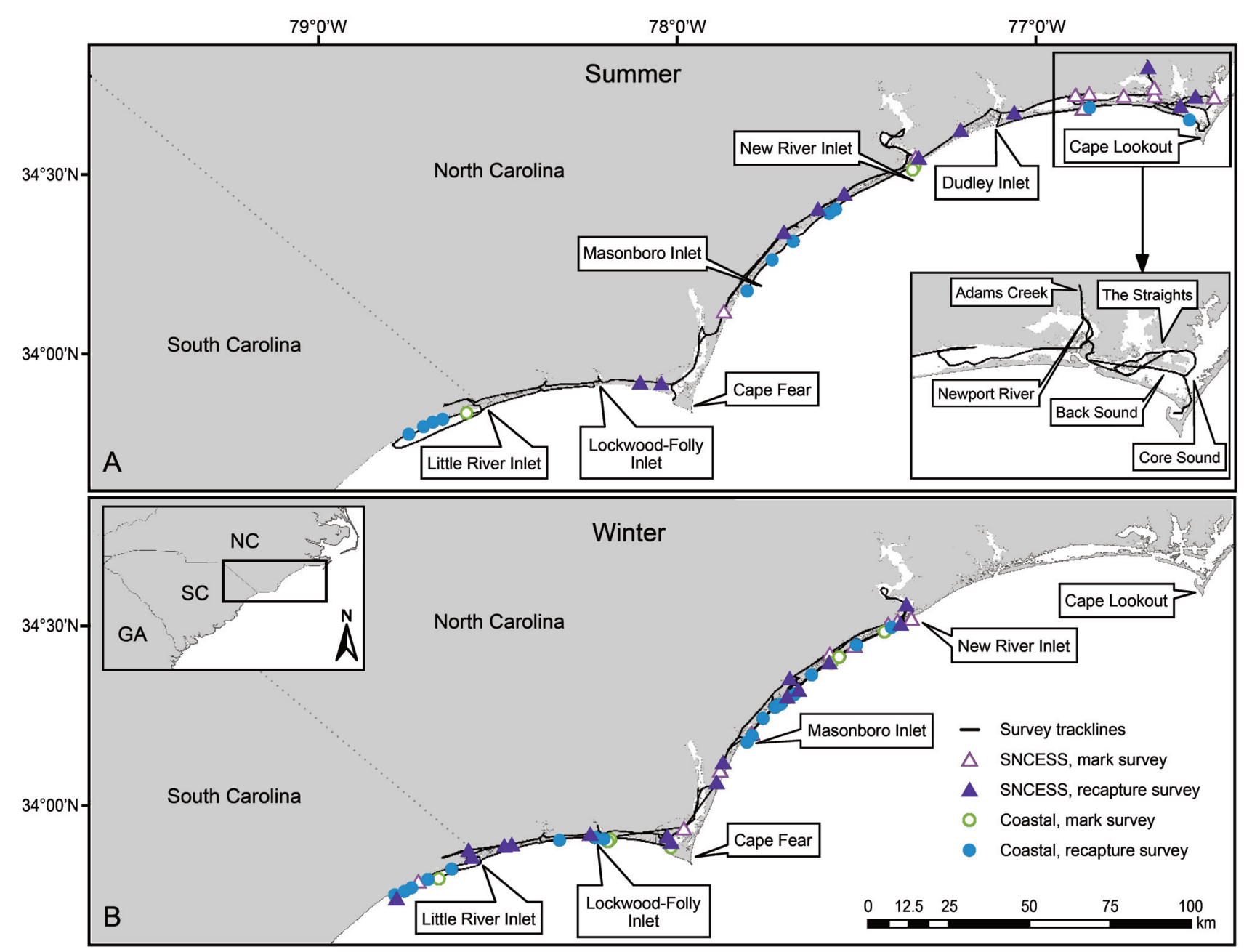

Fig. 1. Survey tracklines and on-effort sightings from the summer (A) and winter (B) of 2014. Symbols represent group sightings from either mark (unfilled) or recapture (filled) surveys and classified as either SNCESS (triangle) or coastal (circle) animals.

Stranding data from inshore waters of southern NC (20072011) found evidence of fisheries interaction on two out of 14 dead dolphins from the SNCESS (Waring et al., 2016). The SNCESS interacts with fishery operations known to cause frequent (Category I) and occasional (Category II) deaths or serious injuries to marine mammals, including the mid-Atlantic gillnet fishery which has the highest estimated impact on bottlenose dolphins along North Carolina (Waring et al., 2016). However, due to low fishery observer coverage, fisheries-related mortality is likely underestimated and PBR could easily be exceeded.

The SNCESS has the smallest population size estimated for estuarine stocks along the US Atlantic seaboard; therefore, this stock may be vulnerable to anthropogenic impacts. Current estimates of abundance and PBR, as well as accurate descriptions of stock distribution, are essential to effective management. The primary objective of this study was to provide an updated estimate of abundance for the SNCESS using mark-recapture photo-identification methods. To improve on previous estimates, we: (1) conducted the most extensive survey to date of the described range of the SNCESS during both summer and winter; (2) applied a combination of catalogue comparisons and predictive models to exclude coastal stock dolphins from the estimate for the estuarine stock; and (3) examined the location and seasonal stability of the southern stock boundary.

\section{METHODS}

Seasonal mark-recapture photo-identification methods Photo-identification surveys, designed with a spatiotemporal mark-recapture framework, were conducted in estuarine and nearshore coastal waters in southern North Carolina throughout the described SNCESS range (Waring et al., 2014). Mark-recapture methods have been extensively used to estimate bottlenose dolphin abundance (Balmer et al., 2008; Read et al., 2003; Speakman et al., 2010; Urian et al., 2014; Wilson et al., 1999) primarily using closed population models. Model assumptions can often be met with careful experimental design (Read et al., 2003; Rosel et al., 2011; Wilson et al., 1999). Surveys in this study were designed to: (1) include most of the described range for the SNCESS stock to minimise violations of the assumptions of homogeneity of capture probability and geographical closure; (2) have short breaks between mark and recapture samples to minimise violations of the assumptions of demographic closure and misidentified marks; and (3) limit the time spent with each dolphin group to $45 \mathrm{mins}$ or less to reduce harassment (Read et al., 2003; Würsig and Jefferson, 1990).

Two seasonal surveys were completed, one in the summer and one in the winter. Each survey was comprised of a single multi-day mark session and a single multi-day recapture session. Surveys sampled both estuarine and near-coastal 
waters, with seasonal differences in total survey length due to the changing seasonal distribution of the stock (Waring et al., 2014). During the summer (June-August 2014), the approximately $539 \mathrm{~km}$ long survey track included $219 \mathrm{~km}$ in coastal waters and $320 \mathrm{~km}$ in estuarine waters. Coastal transects followed the shoreline contour at $300 \mathrm{~m}$ from shore, from the tip of Cape Lookout, NC to Myrtle Beach, SC, excluding a $48 \mathrm{~km}$ stretch from Masonboro Inlet to the mouth of the Cape Fear River and a $25 \mathrm{~km}$ stretch from New River Inlet to Dudley Inlet (Fig. 1A). The southern terminus of this track was $25 \mathrm{~km}$ South of the described SNCESS southern boundary. Although the SAR states the stock boundary for the SNCESS extends out $3 \mathrm{~km}$ from the coast, recent studies have indicated the SNCESS dolphins tend to stay within $0.5 \mathrm{~km}$ from shore when they move into coastal waters (Fleming, 2004; Urian, pers. comm.). Thus, coastal surveys were run only $300 \mathrm{~m}$ from shore to maximise the chance of sighting estuarine dolphins and to minimise encounters with coastal stock dolphins.

Transects in estuarine waters during the summer followed navigational markers in the Intracoastal Waterway (ICW) and adjacent sounds, ranging from the Johnny Causeway landing near Little River, SC, to inland waters near Beaufort, NC, including Back Sound, the Straits, southern Core Sound, portions of the Newport River and Adams Creek (Fig. 1A). Though SNCESS dolphins will sometimes enter the Neuse River and southern Pamlico Sound during summer (Gorgone et al., 2014; Waring et al., 2014), no surveys were conducted in these areas to minimise overlap with the NNCESS (Gorgone et al., 2014; Urian et al., 2014; Waring et al., 2014). Each summer survey track was completed in five survey days. Functionally, each daily survey leg included a coastal track in one direction and an estuarine track in the returning direction. The interval between the summer mark and recapture sessions was 19 days due to an extended period of poor survey conditions.

The winter (December 2014) survey followed the same format, however, the area covered was adjusted to exclude coastal and estuarine waters North of New River, NC (Fig. 1B), consistent with the published SNCESS winter distribution and, again, avoiding overlap with the NNCESS winter distribution. The approximately $353 \mathrm{~km}$ long winter survey track included $162 \mathrm{~km}$ in coastal waters and $191 \mathrm{~km}$ in estuarine waters. Each winter survey track was completed in four survey days and the interval between the winter mark and recapture sessions was one day.

Surveys were conducted aboard a $5.5 \mathrm{~m}$ rigid-hull inflatable boat (RHIB) powered by an $115 \mathrm{hp}$ outboard engine at speeds of $10-14 \mathrm{kts}$ in conditions suitable for dolphin sighting (Beaufort Sea State 3 or less). The field team consisted of at least two observers and one or two photographers/data recorders. Predefined transects were followed with the assistance of a Garmin 76c GPS. When dolphins were sighted, geographical coordinates were recorded, and the vessel left the track. The dolphin group, defined as individuals interacting with one another, moving in the same direction and performing similar behaviours (Urian and Wells, 1996), was approached off-effort. Geographical coordinates were recorded when the individuals were within photographic range. Dorsal fin photographs of all group members were taken at a perpendicular angle (Würsig and Jefferson, 1990) using Canon DSLR cameras EOS Rebel T2i and/or 30D equipped with 100-400mm adjustable lenses. Geo-reference was not image specific, so sighting locations were referenced as the area between the start and end of the encounter rather than a fixed location. The sighting was terminated when all individuals were photographed, $45 \mathrm{mins}$ had elapsed, or the group disappeared. However, when the group size was large (>30 dolphins), the group was subdivided into smaller groups by approaching the head of group and systematically photographing individuals as the group passed by and the $45 \mathrm{mins}$ time restriction was observed separately for each subgroup. At the end of each sighting, geographical coordinates, environmental conditions, group size and composition, predominant behaviour and heading were recorded.

Dorsal fin images and associated survey/sighting data were managed using FinBase (Adams et al., 2006), a modified Microsoft Access database for archiving dolphin sighting data. Dorsal fin images were compared within each sighting and the best right and/or left image of each dolphin was cropped and relabeled with survey and sighting number. For most photographs, image elements such as exposure, lighting and contrast were enhanced using the tools available in Microsoft Photo Gallery 2012. High quality images in which surface features of the fin (scratches, colour variations) were clearly visible did not require enhancement. Images were scored for photographic quality using a weighted scale including the following parameters from Urian et al. (2015): focus; contrast; angle; clarity of the edge features; and whether the dorsal fin was fully visible (PQ1-PQ3). Any photograph below the threshold for quality (PQ3) was removed from the dataset. Finally, individual distinctiveness was scored as 'high' (D1), 'average' (D2), 'low' (D3) or 'not distinct' (D4). For analysis, dorsal fins scored as D1 and D2 were considered marked and D3 and D4 fins were considered unmarked. All catalogue entries for dolphins with marked fins were verified by a second researcher.

\section{STOCK ASSIGNMENT}

Adapting methods by Toth et al. (2012) and Read et al. (2013), we implemented a three-step decision tree to assign each dolphin group to one of two groups: SNCESS or a coastal stock. First, all individuals sighted at least once in estuarine waters (inshore of the coastline) during the current surveys were assigned to the SNCESS following the definition of this stock as described in the 2013 SAR (Waring et al., 2014). Second, dorsal fins photographed during coastal sightings were compared to three datasets: (1) dorsal fins photographed by the authors during estuarine sightings; (2) historical dorsal fin catalogues of estuarine and coastal stock dolphins from southern NC via the Mid-Atlantic Bottlenose Dolphin Catalog (MABDC, Halpin et al., 2009; Urian et al., 1999); and (3) dorsal fins photographed during biopsy sampling surveys in southern North Carolina estuarine waters by National Oceanic and Atmospheric Administration (NOAA) personnel in November and December of 2014. Any coastal sightings that matched 
known estuarine individuals were assigned to the SNCESS. Individuals that were never sighted in estuaries and/or were classified as members of the coastal stock in historical catalogues were assigned to a coastal stock. Third, statistical modelling was used to designate coastal sightings into either stock, as described below.

Read et al. (2013) noted that in North Carolina '[d]olphins from both [coastal] migratory stocks carry heavy loads of [the pseudo-stock barnacle] Xenobalanus' and also that 'estuarine animals were observed in relatively small groups, close to shore, in shallow water and in relatively close proximity to an inlet'. Therefore, we used the approach of Toth et al. (2012) to perform a hierarchical cluster analysis (Ward's method and average linkage method) on all coastal sightings during seasonal surveys to detect the presence of clusters based on one of the following variables: distance from shore; distance from the closest inlet; water depth; group size; and presence and abundance of the pseudo-stock barnacle Xenobalanus globicipitis. Analyses were conducted using the program Statistical Package for the Social Sciences (SPSS 22). Resulting clusters were assessed in comparison to coastal sightings of known stock identity based on the first two stages of our decision tree. The variable that placed the most confirmed SNCESS coastal sightings in the same cluster was chosen as the explanatory variable. A discriminant function analysis (DFA) was then employed to evaluate which of the remaining variables could be used as stock predictors.

Distance from shore and distance from the closest inlet were measured as the linear distance between the initial sighting coordinates and the corresponding feature using the proximity tools (Data Management Toolbox) in ArcMap 10.2. Depth was recorded for each sighting using a Lowrance GPS equipped with sonar. Group size was estimated in the field as a consensus between all researchers aboard the vessel and reviewed after photo-analysis. The presence of $X$. globicipitis was measured as the proportion of fins in the group carrying the barnacle and the $X$. globicipitis abundance was measured as none ( 0 barnacles/dolphin), light (1-5 barnacles/dolphin), medium ( $6>$ barnacles and $<1 / 3$ of the fin covered/dolphin) and heavy ( $\geq 1 / 3$ fin covered/dolphin) based on the median $X$. globicipitis abundance in each group (modified from Toth-Brown and Hohn, 2007). An independent samples Mann-Whitney U-Test was performed to test the assumption that there was a significant difference in the distribution of the cluster analysis variables between the SNCESS and a coastal stock(s). The abundance of $X$. globicipitis on the fins and the proportion of the group carrying the barnacle were also tested on estuarine sightings and coastal sightings of dolphins with known stock identity to increase sample size.

\footnotetext{
Abundance estimate

Abundance estimates were calculated using only on-effort dolphin sightings classified as estuarine stock animals (SNCESS) and only fins that met the criteria for individual distinctiveness and photographic quality. Three different approaches were used to calculate abundance, each assuming a closed population: the Chapman modification to the Lincoln-Petersen method, which includes a bias correction for small sample size (Seber, 1982); package Rcapture
}

(Baillargeon and Rivest, 2007) in program R (R Development Core Team, 2015); and program MARK 6.2 (Cooch and White, 2006). For the two statistical packages, data were fit to two abundance models: the null model $\mathrm{M}_{0}$, which assumes that capture probability is constant for all individuals across all survey sessions; and model $\mathrm{M}_{\mathrm{t}}$, which assumes temporal variation in capture probability between mark and recapture sessions (Amstrup et al., 2005; Williams et al., 2002). Two other potential models $M_{b}$ and $M_{h}$, were not appropriate for our dataset and were not used. Specifically, model $\mathrm{M}_{\mathrm{b}}$ assumes a learned behavioural response to capture which results in different capture probabilities after first capture. This was inconsistent with observed responses to previous photo-identification surveys (Read et al., 2003; Würsig and Jefferson, 1990). Model $\mathrm{M}_{\mathrm{h}}$ assumes variation in individual capture probability among samples, but it requires more than one recapture session and was therefore not appropriate for our data (Amstrup et al., 2005; Williams et al., 2002). For package Rcapture, the AIC value was used to assess model fitness and selection (Burnham and Anderson, 2002), and estimates were then recalculated using the bias corrected version of the selected best model. Rcapture has a written function that uses frequency modifications in Poisson regression (Rivest and Lévesque, 2001) to apply small sample size corrections (Rivest and Baillargeon, 2014).

Since these estimates included only marked dolphins, the total population size was estimated by dividing the 'marked' estimate by the proportion of marked animals in the population, i.e. the distinctive rate (Wilson et al., 1999). The distinctive rate was calculated for each sighting group as an average of the total number of marked individuals divided by the total number of individuals in the group and was calculated only for events with $100 \%$ photographic coverage (Wilson et al., 1999). Final variance and standard errors (SE) were calculated using the delta method (Wilson et al., 1999). The confidence intervals (CI) were calculated using the log-normal approximation (Wilson et al., 1999), given that confidence intervals calculated using log-linear profile likelihood are not suitable for closed population models (Lukacs, 2013). Finally, the most parsimonious approach was selected based on the lowest coefficient of variation $(\mathrm{CV})$ value.

\section{Southern boundary and seasonal movements}

In order to confirm the southern boundary for the SNCESS, additional year-round photo-identification surveys were conducted along pre-defined coastal and estuarine transects to the North and South of the currently defined southern boundary at Little River Inlet (NC/SC border) (Fig. 1A). Specifically, in North Carolina, a $25 \mathrm{~km}$ long coastal track was run at $0.5 \mathrm{~km}$ from shore and a $28 \mathrm{~km}$ inshore track was run along the Intracoastal Waterway (ICW) from the Lockwood-Folly Inlet in Holden Beach, NC, to the Johnny Causeway landing in Little River, SC. In South Carolina, where no additional estuarine track was available, two $25 \mathrm{~km}$ coastal tracks were run parallel to shore at $0.5 \mathrm{~km}$ and $1.5 \mathrm{~km}$ from shore ranging from Little River Inlet to northern Myrtle Beach. These surveys were conducted under the same platform, protocol and photo-identification methodology as described for the seasonal surveys. 
Data from the seasonal mark-recapture surveys and the year-round photo-identification surveys were pooled to identify differences in the seasonal distribution of SNCESS dolphins and to identify the southernmost sightings of known SNCESS dolphins. Comparisons were also made with the dorsal fin catalogue from a separate, year-round photoidentification survey conducted from 2013-2015 along $50 \mathrm{~km}$ of coastline centered on Murrells Inlet, SC, $58 \mathrm{~km}$ southwest of Little River Inlet along the coast (Dunn et al., 2014; Silva, 2016). We defined a warm season (MaySeptember) and a cool season (October-April), based on the timing of documented seasonal shifts by the SNCESS and on the migratory timing of the nearby Southern Migratory Coastal Stock (Waring et al., 2016). Within season movements of SNCESS dolphins were investigated by plotting the sightings of all confirmed SNCESS individuals, from any of these surveys, that were sighted two or more times during different survey days (on or off effort). Seasonal movements were investigated by expanding the afore mentioned dataset to dolphins that were sighted two or more times in both warm (June-September 2014 or May-August 2015) and cool seasons (October 2014-April 2015). Sighting coordinates were plotted in ArcMap 10.2, connected with a line depicting the movement of each dolphin (Data Management Toolbox) and compared within and across seasons.

\section{RESULTS}

\section{Field effort}

During the summer, the mark and recapture sessions were each completed in five non-consecutive survey days (Table 1). Both survey sessions and the inter-session interval took longer than originally intended due to extended periods of poor survey conditions. Due to this extended time frame, a potential additional recapture survey was ruled out to avoid violating the closed population assumption. A total of 126 individuals were considered marked, and of those, images from 111 dolphins met the criteria for photographic quality. Twenty sighting events occurred in the Intracoastal Waterway and surrounding estuaries, while coastal sightings included three groups within $500 \mathrm{~m}$ of the coast, 11 groups between $500 \mathrm{~m}$ and $1 \mathrm{~km}$ from the coast and one group beyond $1 \mathrm{~km}$ from the coast.

During the winter, each mark and recapture session was completed in four non-consecutive days (Table 1). A total of 90 individuals were considered marked from which 89 met the image quality criteria. Twenty-one sighting events occurred in the Intracoastal Waterway and surrounding estuaries, while coastal sightings included nine groups within $500 \mathrm{~m}$ of the coast, 22 sightings between $500 \mathrm{~m}$ and $1 \mathrm{~km}$ from

Table 1

Field effort for the seasonal mark-recapture surveys.

\begin{tabular}{lrr}
\hline Season & Summer 2014 & Winter 2014 \\
\hline Mark session & Jun. 12-30 & Dec. 2-15 \\
Recapture sessions & Jul. 20-Aug. 16 & Dec. 17-27 \\
Total hours on effort & 70 & 39.5 \\
No. dolphin groups & 35 & 64 \\
No. dolphins photographed & 241 & 297 \\
No. marked individuals & 126 & 90 \\
\hline
\end{tabular}

the coast and 12 sightings beyond $1 \mathrm{~km}$ from the coast. During the winter, more dolphin groups were observed in coastal waters. However, the high prevalence of the barnacle $X$. globicipitis on dorsal fins in coastal waters possibly obscured identification features, thus fewer individuals met the photographic quality criteria.

The year-round photo-identification surveys centered in Little River were carried out in August and October/ November 2014 and March, May and August 2015. Each survey was completed within 1-2 days, during which approximately $140 \mathrm{~km}$ were surveyed in $6.4 \mathrm{hrs}$ on average. Three survey sessions were completed in August 2014 and two survey sessions were completed thereafter; however, only one survey was completed in January 2015 due to extended windy conditions. Eighty-three dolphin groups were sighted (75 on-effort) and 490 individuals were identified (177 marked dolphins).

\section{Stock assignment}

Good quality photographs were obtained from 30 of 35 group sightings during the summer survey and 60 of 64 group sightings during winter survey. A total of nine dolphins freeze-branded during previous studies in North Carolina (summarised in Waring et al., 2016) were photographed: four during the summer survey, two during the winter survey and three during both summer and winter surveys. Sixteen of 30 dolphin groups from the summer survey and 20 of 60 groups from the winter survey were sighted in estuarine waters and, by definition, were classified as members of the SNCESS. Of the remaining 54 coastal group sightings, one in summer and six in winter were classified as SNCESS because they included individual dolphins already classified as members of the SNCESS based on either our own estuarine sightings, estuarine sightings from the NOAA 2014 biopsy surveys, or the MABDC historical catalogue. In contrast, three coastal sightings in summer were classified as coastal stock dolphins based on matches with known coastal stock animals in the MABDC. After these initial classifications, 47 coastal sighting groups remained undefined. Statistical modelling was then applied to identify the remaining groups and to test the likelihood of our initial classifications.

The results of the Wards linkage cluster analysis, using $X$. globicipitis abundance as the explanatory variable, defined two distinct clusters of dolphins in coastal sightings (Fig. 2). A total of 56 coastal sightings were used in the analysis, 17 in the summer and 39 in the winter. Fifteen coastal sightings were placed in cluster one (SNCESS) and the remaining 41 sightings were placed in cluster two (Coastal) (Fig. 2). Individual dolphins from nine of the 15 coastal sightings assigned to the SNCESS were previously sighted in estuarine waters (Urian, 2016) supporting the modelling classification. One of the coastal sighting groups that included an individual identified as SNCESS was classified by the cluster analysis as a coastal group and was thus classified as a 'mixed' group sighting. The discriminant function analysis (DFA) defined $X$. globicipitis abundance and presence as grouping variables (Fig. 3) and placed dolphins into the predicted stock with $94.6 \%$ accuracy (Canonical Correlation $=0.821$, eigenvalue $=2.62$, Wilks' Lambda $=0.327$ ). Distance from shore and water depth were 


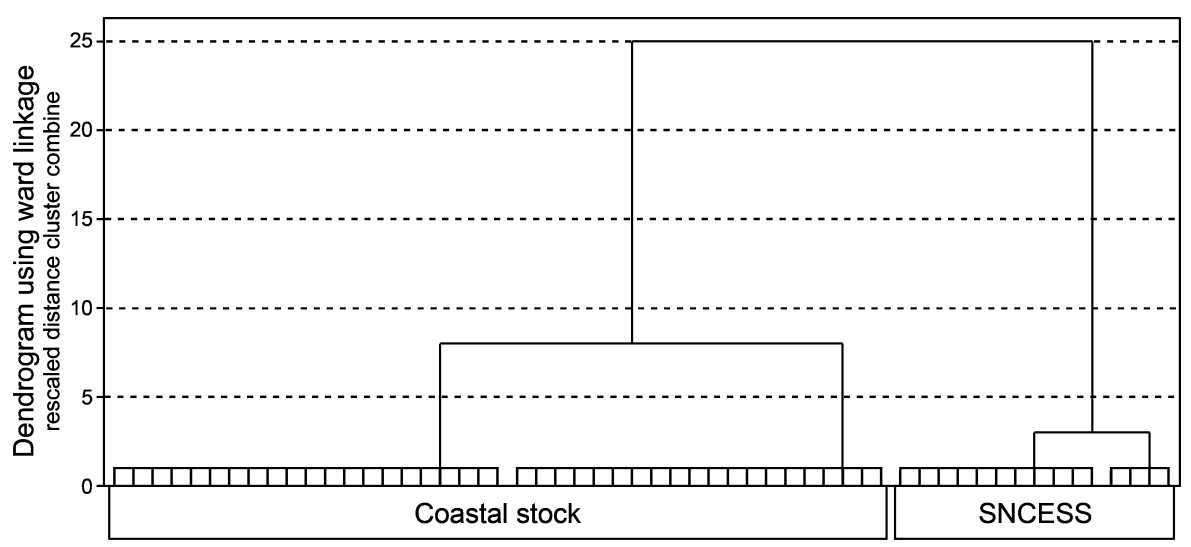

Fig. 2. Ward Linkage Method Dendrogram depicting the two clusters based on differences in the median abundance of the pseudo-stalk barnacle Xenobalanus globicipitis for each dolphin group.

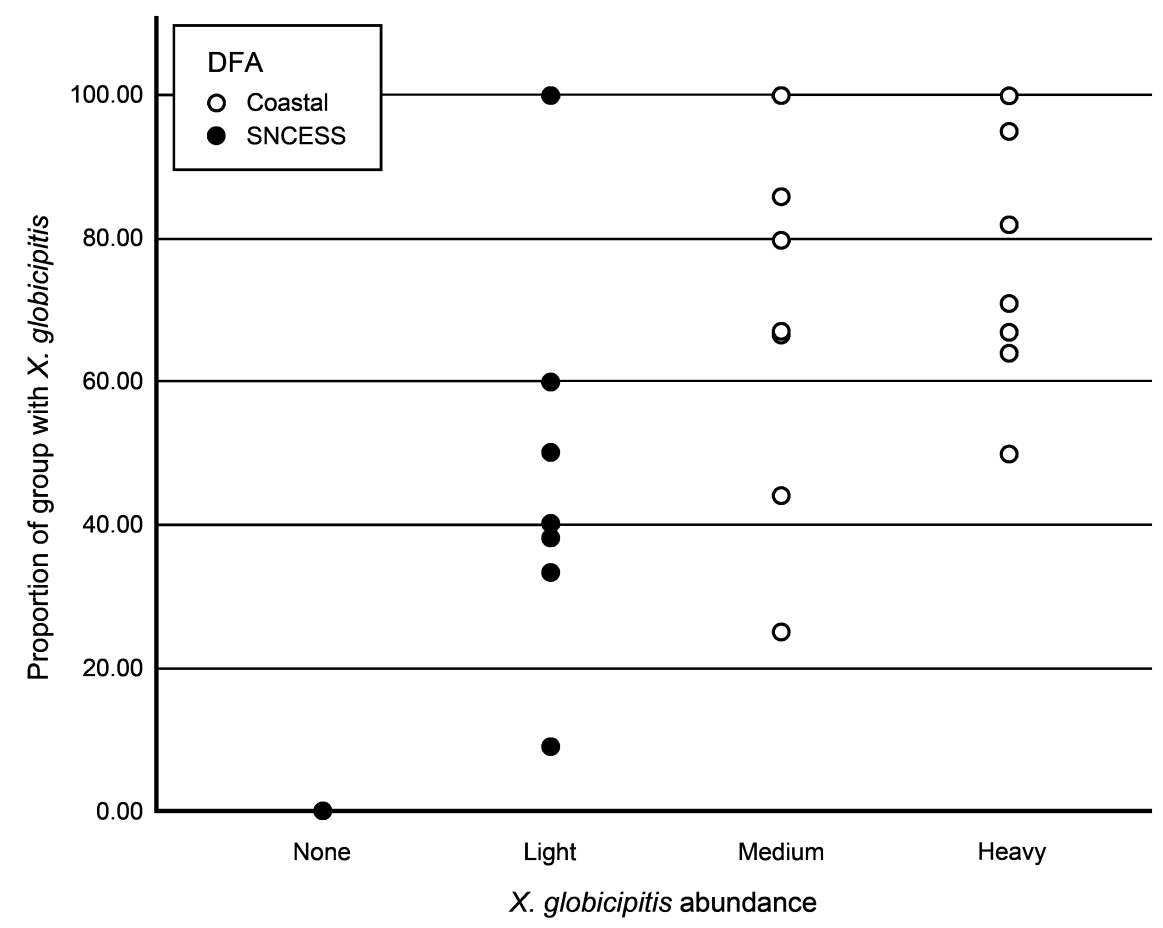

Fig. 3. Discriminant Function Analysis grouping of coastal sightings based on the median abundance of the barnacle on the dorsal fins and the proportion of the group carrying the barnacle.

Table 2

Mean/median and standard deviation (SD) of variables tested as stock membership predictors. Mann-Whitney U test found significant differences between the estuarine and coastal clusters on four of the six modelling variables.

\begin{tabular}{lcrrrc}
\hline & \multicolumn{2}{c}{ Possible SNCES Stock } & \multicolumn{2}{c}{ Possible Coastal Stock } & Mann-Whitney \\
Modelling Variables & Mean/Median & SD & Mean/Median & SD & U-test \\
\hline Percent of group with barnacle & 43.99 & 36.84 & 90.86 & 18.14 & $\mathrm{p}=0.000^{*}$ \\
Abundance (barnacle) & 0.79 & 0.58 & 2.38 & 0.55 & $\mathrm{p}=0.001^{*}$ \\
Distance from shore (m) & 615.66 & 685.98 & 760.84 & 357.41 & $\mathrm{p}=0.014^{*}$ \\
Depth (m) & 6.49 & 2.75 & 8.77 & 2.27 & $\mathrm{p}=0.014^{*}$ \\
Distance from inlet (m) & 8848.93 & 7484.44 & 8859.21 & 7371.73 & $\mathrm{p}=0.224$ \\
Revised group size & 6.93 & 5.76 & 14.13 & 20.39 & $\mathrm{p}=0.397$ \\
\hline
\end{tabular}

not effective discriminant parameters, likely due to the proximity of transects to the shoreline.

Coastal sightings classified either as SNCESS or a coastal stock were significantly different for: the proportion of dolphins with $X$. globicipitis (Mann-Whitney $\mathrm{U}$ test, $\mathrm{p}=0.000$ ), the $X$. globicipitis abundance (Mann-Whitney U-test, $\mathrm{p}=0.001)$, depth (Mann-Whitney U test, $\mathrm{p}=0.014$ ) and distance from shore (Mann-Whitney $U$ test, $\mathrm{p}=0.014$ ) (Table 2). Distance from the nearest inlet and group size were not significantly different between the SNCESS and coastal clusters (Mann-Whitney $U$ test, $p=0.224$ and 0.397, respectively) (Table 2), although 13 of the 16 coastal sightings with more than 10 individuals were classified as a coastal stock. In addition, a Mann-Whitney U test was performed on 43 coastal and estuarine group sightings attributed to SNCESS dolphins and three group sightings attributed to coastal dolphins. Significant differences were found for $X$. globicipitis abundance (Mann-Whitney U test, $\mathrm{p}=0.012$ ) and 
for the proportion of dolphins in the group with $X$. globicipitis on the dorsal fin (Mann-Whitney U test, $p=0.031$ ).

During the summer survey, only $16 \%$ of group sightings attributed to the SNCESS occurred in coastal waters and these sightings were all within $600 \mathrm{~m}$ from shore. In contrast, $31 \%$ of winter group sightings attributed to the estuarine stock occurred in coastal waters, including one between $600 \mathrm{~m}$ and $1 \mathrm{~km}$ from shore and two beyond $1 \mathrm{~km}$ from shore. In addition, more dolphins were photographed in both estuarine and coastal waters in the winter (six of 45) than in the summer (one of 65). The mean size of dolphin groups assigned to the SNCESS was significantly higher during the summer $(\mathrm{n}=19, \overline{\mathrm{x}}=9.05)$ than the winter $(\mathrm{n}=31, \overline{\mathrm{x}}=4.57)$ (Mann-Whitney $\mathrm{U}$ test, $\mathrm{U}=406, \mathrm{p}=0.025$ ), but no significant difference in group size was found between SNCESS sightings in coastal waters $(\mathrm{n}=14, \overline{\mathrm{x}}=4.86)$ and estuarine waters $(\mathrm{n}=36, \overline{\mathrm{x}}=6.75)$ (Mann-Whitney U test, $\mathrm{U}=241.5, \mathrm{p}=0.827)$.

\section{SNCESS abundance estimates}

A total of 110 individuals were identified as members of the SNCESS during on- and off-effort sighting events from the seasonal photo-identification surveys. Of these, 65 individuals were identified during the summer of which 58 were sighted during on-effort events and five were resighted during the recapture session. In the winter, 45 individuals were identified and 36 of those were sighted on-effort, including three dolphins that were resighted during the recapture session. Even though the winter survey included 25 individuals also sighted during the summer survey, the discovery curve did not reach a plateau, indicating that not all individuals within the population were identified (Fig. 4).

Although variations in capture probability occur with bottlenose dolphin populations (Read et al., 2003; Urian et al., 2014; Wilson et al., 1999), model $\mathrm{M}_{\mathrm{t}}$ did not fit the data, likely because the low number of recaptured individuals was insufficient to detect differences in capture probabilities. Estimates generated with the Chapman LP model yielded lower coefficient of variation $(\mathrm{CV})$ values and thus were selected as the most parsimonious estimates for both summer and winter (Table 3 ). The bias corrected null model $\left(\mathrm{M}_{0}\right)$ best fit the data, estimating abundance at 272 dolphins (95\% CI 189-390, CV $=0.32$ ) in the summer and 206 dolphins $(95 \%$ CI $100-423, C V=0.38)$ in the winter. Seasonal abundance estimates from the present study are higher than the previous 2000 and 2006 estimates for the SNCESS, though no significant difference was found as estimated CIs overlap (Table 4).

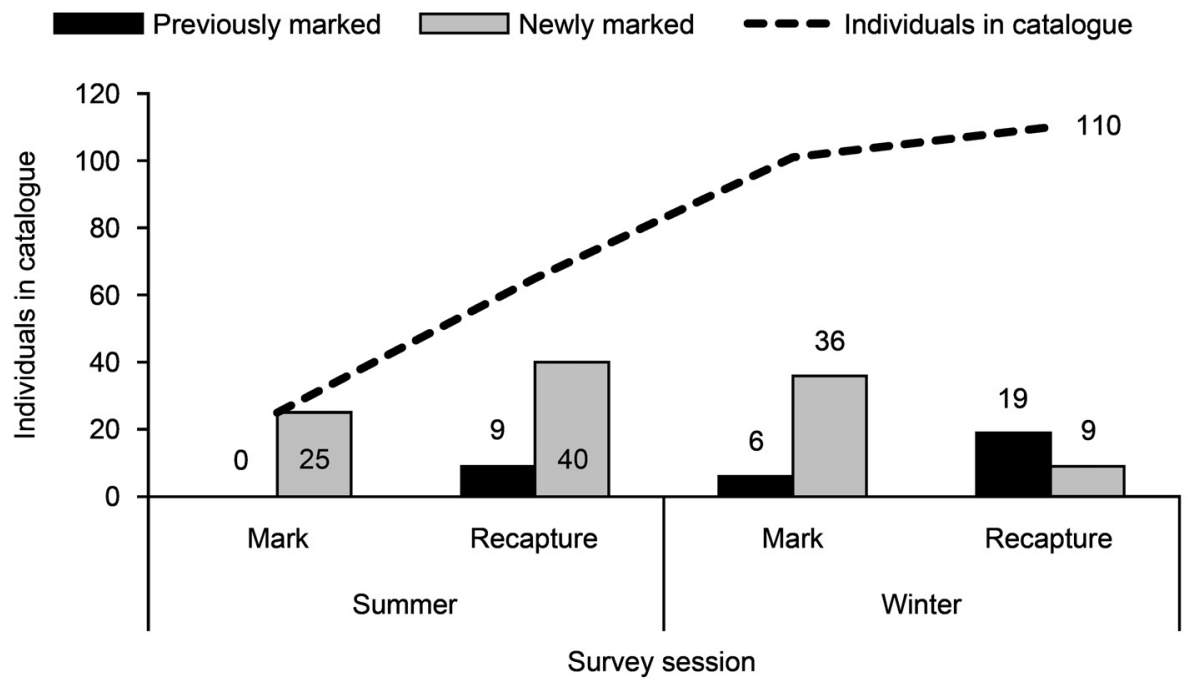

Fig. 4. Discovery curve of marked SNCESS individuals photographed during seasonal mark-recapture surveys. The dashed line, indicating the cumulative number of identified individuals, did not reach a plateau thus the entire population has not been identified.

Table 3

Estimates of abundance generated under different approaches.

\begin{tabular}{|c|c|c|c|c|c|c|c|}
\hline \multirow[b]{2}{*}{ Approach } & \multirow[b]{2}{*}{ Model } & \multicolumn{3}{|c|}{ Summer } & \multicolumn{3}{|c|}{ Winter } \\
\hline & & Estimate & $95 \% \mathrm{CI}$ & $\mathrm{CV}$ & Estimate & $95 \% \mathrm{CI}$ & $\mathrm{CV}$ \\
\hline Chapman LP & $\mathrm{M}_{0}$ & 272 & $189-390$ & 0.32 & 206 & $100-423$ & 0.38 \\
\hline Rcapture & $\mathrm{M}_{0}$ & 283 & $146-548$ & 0.35 & 208 & $94-459$ & 0.42 \\
\hline MARK & $\mathrm{M}_{0}$ & 316 & $152-656$ & 0.39 & 247 & $98-621$ & 0.50 \\
\hline
\end{tabular}

Table 4

Comparisons between previous abundance estimates for the SNCESS and the current study.

\begin{tabular}{cccccll}
\hline \multicolumn{1}{c}{ Model } & Estimate & $95 \%$ CI & CV & \multicolumn{1}{c}{ D and PQ } & Effort Season & Source \\
\hline Darroch $\mathrm{M}_{\mathrm{t}}$ & 141 & $112-200$ & 0.15 & D1 and D2, PQ1 and PQ2 & Summer 2000 & Read et al., 2003 \\
Darroch $\mathrm{M}_{\mathrm{t}}$ & 188 & $118-257$ & 0.19 & D1 and PQ 1 only & Summer 2006 & Urian et al., 2013 \\
Chapman LP & 272 & $189-390$ & 0.32 & D1 and D2, PQ1 and PQ2 & Summer 2014 & Present study \\
Chapman LP & 206 & $100-423$ & 0.38 & D1 and D2, PQ1 and PQ2 & Winter 2014 & Present study \\
\hline
\end{tabular}




\section{Southern boundary and seasonal movements}

No individuals classified as SNCESS were observed in inshore or coastal waters southwest of Lockwood-Folly Inlet, $\mathrm{NC}$, during the summer survey (Fig. 1A). In winter, however, dolphin distribution shifted southward, including inshore and coastal waters from Lockwood-Folly Inlet, NC, to South of Little River Inlet, SC (Fig. 1B). SNCESS dolphins were also resighted during concurrent year-round surveys based out of Murrells Inlet, SC (Silva, 2016), and when these surveys were examined in combination with the SNCESS surveys, an even clearer pattern of within-season and between-season movements appeared (Fig. 5).
The distribution of all 18 dolphins sighted in both seasons shifted southward in the cool season, with multiple individuals travelling well South of the currently defined southern boundary for the stock (Fig. 5C). Several of these individuals were observed to travel over $150 \mathrm{~km}$ between sightings. The southernmost sighting consisted of five individuals assigned to the SNCESS and occurred on 10 March 2015 off Pawleys Island, SC $\left(33^{\circ} 26^{\prime} 30^{\prime \prime} \mathrm{N}, 79^{\circ} 6^{\prime} 21^{\prime \prime} \mathrm{W}\right)$, approximately $70 \mathrm{~km}$ South of the currently recognised southern stock boundary at Little River Inlet (Silva, 2016).

As temperatures warmed, the distribution of SNCESS dolphins shifted North again, and except for one sighting in
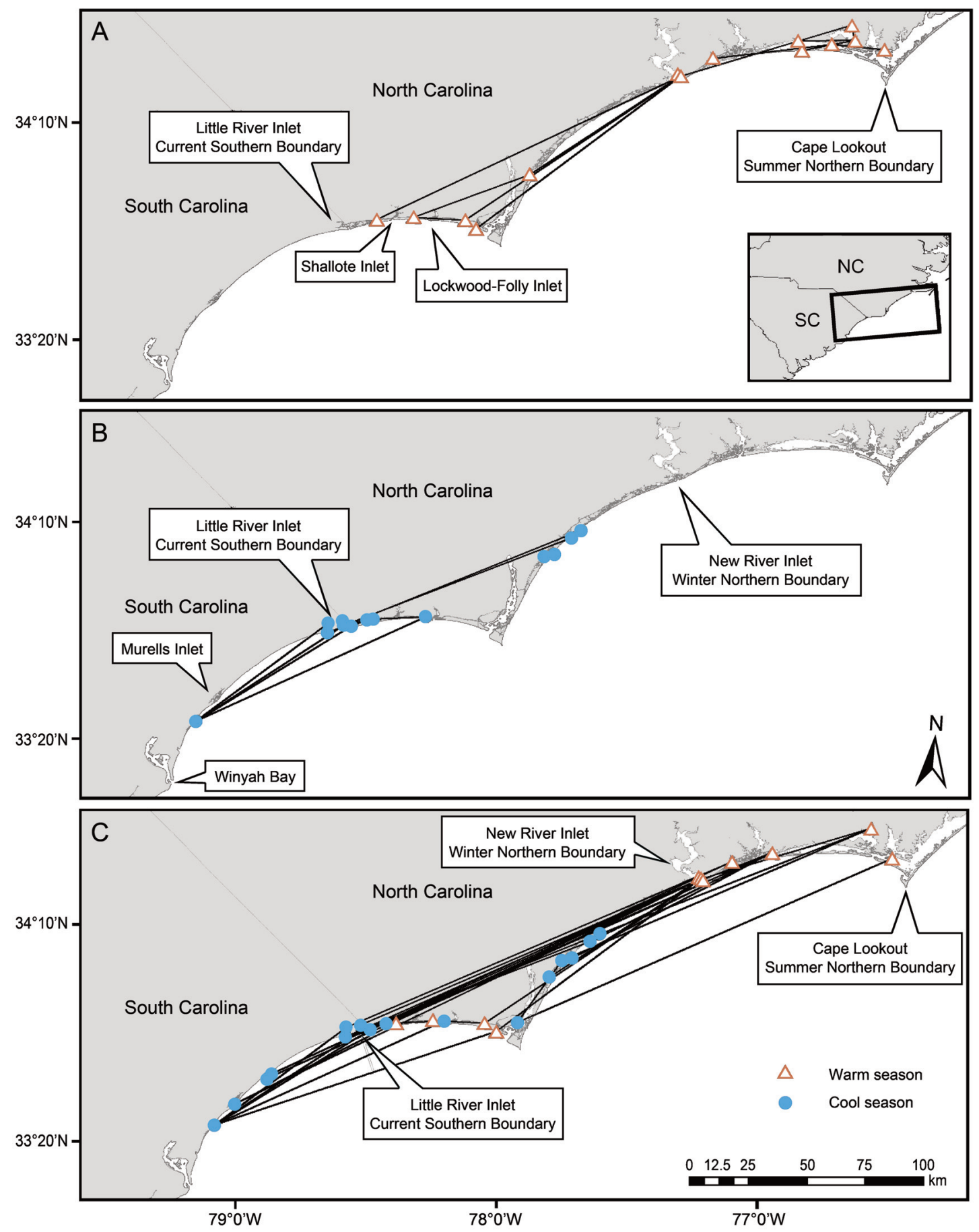

Fig. 5. Individual movements of SNCESS dolphins within seasons (A and B) and across seasons (C). During the warm months (A) dolphins were resighted either northward or southward of New River and few sightings occurred southwest of LockwoodFolly Inlet. During the cooler months (B), dolphins were resighted southwest of Lockwood-Folly Inlet and ventured outside the currently defined southern boundary in Little River (B). All individuals moved South as seasons changed from warm to $\operatorname{cool}(\mathrm{C})$. 
May, all warm season sightings were North of Shallotte Inlet in southern North Carolina (Fig. 5A). Resighting patterns suggest that the summer habitat may be further partitioned North and South of New River, NC. For both the warm and cool seasons, however, resighting patterns indicate that dolphins range widely even within seasons, in some cases greater than $100 \mathrm{~km}$ and covering more than half of the published stock range (Figs 5A and 5B).

\section{DISCUSSION}

This study provides an update to the expired abundance estimate for the Southern North Carolina Estuarine System Stock of bottlenose dolphins, based on the most extensive survey effort to date for this stock and utilising a novel approach to distinguish between estuarine and coastal dolphins in nearshore coastal waters. Movements within a season suggest that many SNCESS dolphins are wideranging within the stock boundaries. Seasonal movements observed for SNCESS individuals indicate substantial changes during the cooler months including the increased use of coastal waters, a southern shift in distribution and a revised location for the southern stock boundary.

SNCESS dolphins were observed in coastal waters more frequently and farther offshore in winter, potentially reducing encounter rates for winter surveys. This movement is likely a response to the emigration of prey species from salt marsh estuarine systems into coastal waters as water temperatures decrease (Rountree and Able, 2007; Young and Phillips, 2002). Reduced abundance estimates and encounter rates during the cooler months were observed in other nearby estuarine systems in South Carolina (Brusa et al., 2016; Speakman et al., 2010).

The northern stock boundary has been documented to shift South in the winter to approximately New River, NC (Urian et al., 2014; Waring et al., 2016), but this study was the first to investigate the southern stock boundary. Our findings show a general shift southward of the southern boundary during the cool season, both in estuarine and coastal waters. In the warm season, only one SNCESS sighting occurred southwest of Shallotte Inlet similar to a previous survey by Read et al. (2003) which found no dolphins southwest of Cape Fear, NC. During the cool season however, numerous SNCESS dolphins were sighted in estuarine and coastal waters between Cape Fear and the currently defined southern stock boundary at Little River Inlet, SC. Moreover, multiple cool season SNCESS sightings were made in coastal waters South of Little River, as far as Pawley's Island Inlet, suggesting a revision is needed for the southern stock boundary. There is no connection between estuarine and coastal waters along this section of the coast, thus these sightings represent at least a $70 \mathrm{~km}$ foray along the coast from Little River Inlet to Pawley's Island. Interestingly, this revised southern boundary for the SNCESS overlaps with the northern range of the Northern South Carolina Estuarine System Stock (Waring et al., 2016).

Within-season movements were substantial, with distances between resightings over $100 \mathrm{~km}$ in both the warm and cool seasons. Resightings occurred between New River, NC and Pawley's Island, SC in the cool season and generally North of Shallotte Inlet, NC in the warm season. Warm season resighting patterns suggest potential habitat partitioning North and South of New River, NC. If so, it would roughly correlate to habitat differences, with primarily narrow, linear waterways and small salt marsh systems to the South and larger sounds and estuarine river mouths to the North.

This was the first estuarine stock abundance study to use a modelling approach to distinguish between estuarine and coastal stock animals observed during coastal sightings. Modified from Toth et al. (2012), our model separated these groups based on the presence and abundance of the barnacle $X$. globicipitis. Water depth and distance from shore were also significantly different for coastal and estuarine stock sightings but were not a grouping factor according to the results of the DFA, likely because survey tracks were run close to shore with little variability in these parameters. In contrast, group size was not significantly different between coastal and estuarine stock sightings, even though individuals from coastal stocks tend to travel in larger groups (Read et al., 2013). The clusters defined by our model were well-supported by catalogue comparisons with known SNCESS and coastal individuals. Such verification would not be possible in a less-studied area without historical dorsal fin catalogues.

The ecological reason behind stock-specific distribution patterns of $X$. globicipitis is not clearly understood. The barnacle is found exclusively attached to the fins of cetaceans in all oceans worldwide, apparently associated with areas of high primary production (Kane et al., 2008; Toth-Brown and Hohn, 2007). Spawning may occur twice a year as reported in Peru (Van Waerebeek et al., 1993), however it is unclear when it occurs in the Atlantic Ocean. Recruitment of the larvae to cetacean fins appears to follow an aggregated pattern (Kane et al., 2008) induced by chemical cues from the host (Carrillo et al., 2015) and patchy distribution of the larvae (Kane et al., 2008). Settlement patterns on specific dolphin stocks may reflect differences in dolphin ranging patterns and/or the life cycle of $X$. globicipitis, reportedly lasting 5-6 months (Van Waerebeek et al., 1993). It is presumed that the barnacles may be stenohaline, and therefore would eventually perish on estuarine dolphin fins (Urian et al., 2019).

In our study, there was no change in the median $X$. globicipitis abundance for estuarine dolphins between warm and cool months. However, the median $X$. globicipitis abundance increased on coastal dolphins during the winter months. Unfortunately, the stock structure of coastal dolphins in southern North Carolina is poorly understood. Though the presence of at least one coastal stock is obvious in this study as well as previous studies (Read et al., 2003; Urian et al., 2014), no coastal stock of bottlenose dolphins is currently defined for this region of the coast during summer or winter (Waring et al., 2016). In addition, it is unclear whether the coastal stock dolphins observed in this study are members of an undescribed stock or if they are members of neighbouring coastal stocks, which would require a revision of the range for those stocks. Moreover, recent evidence suggests that coastal dolphins found in southern NC during the summer emigrated from the area and were replaced by different individuals during the winter (Silva, 2016), thus the increased barnacle coverage could be indicative of a shift in the distribution of coastal stocks. 
Though the summer and winter confidence intervals overlap, we argue that the summer estimate of 272 (95\% CI 189-390) best represents total stock abundance based on agreement between the survey design and the stock distribution. During the winter survey, encounter probabilities decreased because the distribution of SNCESS dolphins expanded outside the survey area to the South and potentially farther offshore, thereby negatively biasing the abundance estimate. The summer survey, however, effectively covered the summer range for the stock, including both estuarine and nearshore waters, and since sightings of coastal stock dolphins were effectively excluded from our estimate, the summer survey provides a robust estimate for the entire estuarine stock.

The summer surveys spanned a three-month period due to poor survey conditions, which was longer than we preferred for the assumption of closure. However, the summer range is stable for this stock (Read et al., 2003; Urian et al., 2013), and coastal stock dolphins were eliminated from our markrecapture analyses, consequently immigration/emigration during the survey period was unlikely supporting geographical closure. Calves and neonates, with their potentially higher mortality rates (Speakman et al., 2010), generally lack substantial marks, therefore they were not included in the 'mark' estimate but rather indirectly included in the mark-recapture analyses though the theta parameter. In addition, it is unlikely that the rate of addition of new juveniles to the marked population substantially differed from the rate of removal from natural mortality during this three-month period, supporting demographic closure. In contrast to summer, the winter surveys were completed in only 25 days, including a short one-day interval between the mark and recapture sessions which took advantage of a narrow window of good survey conditions. This short interval may not have allowed for population mixing between sessions. Given the consistent tracks for the mark and recapture surveys, a lack of mixing would be expected to result in an increased percentage of resightings; however, this did not occur.

Our point abundance estimate is higher than the estimates from the previous two SNCESS surveys in 2000 (Read et al., 2003) and 2006 (Urian et al., 2013), but the differences are not significant, as the confidence intervals overlap. Read et al. (2003) surveyed only in estuarine waters, resulting in a negatively biased estimate, and though Urian et al. (2013) surveyed in both estuarine and coastal waters, their survey tracks covered substantially less of the stock range than the current study, particularly in coastal waters. Direct comparisons between these three estimates are therefore problematic, and the increase in estimated abundance should not be interpreted as evidence that the stock is increasing. Nonetheless, it is encouraging that the SNCESS shows no obvious signs of depletion following an unusual mortality event of US Atlantic coast bottlenose dolphins (Morris et al., 2015). Although this epizootic was believed to have mainly impacted coastal stock animals (Morris et al., 2015), some estuarine individuals were impacted in North Carolina (BDTRT, 2017).

With the updated point estimate of 272 dolphins, the SNCESS still has the smallest estimated abundance of any bottlenose dolphin stock along the US East coast. The stock is vulnerable to low levels of fisheries interactions and gillnet interactions have been documented in southern North Carolina (Waring et al., 2016). If these interactions occur in coastal waters, the challenge will be to distinguish between impacted SNCESS and coastal stock animals, especially if these interactions occur during the cool months when the use of nearshore coastal waters by estuarine dolphins increases. With such a small estuarine stock, it may be possible to do so based on a more frequent photo-identification effort in the estuarine system.

\section{ACKNOWLEDGEMENTS}

This research was conducted under NMFS General Authorization Letter 16104. Research funding was provided by the North Carolina Sea Grant Consortium and a Coastal Carolina University Graduate Student Incentive Grant. Additional funding for personnel during data analysis was generously provided by the Rare Species Fund. We thank Lance Garrison, Patricia Rosel and Andy Read for assisting with the study design. We are in debt to Jeff Adams who created database queries that were essential to data analysis. Annie Gorgone, Todd Speakman and Eric Zolman were very kind to share photographic data from NOAA's biopsy surveys in southern NC during the fall of 2014. We thank bottlenose dolphin researchers that have shared their dorsal fin catalogues with the Mid-Atlantic Bottlenose Dolphin Catalog (MABDC). We are immensely grateful for the assistance of Kim Urian, whose effort and dedication with comprehensive catalogue comparisons and match confirmations via the MABDC were essential for the success of this project. For their assistance in the field, we thank Sam Gary, Brandon Tierney, Amy Grogan, Kristen Trevey and Kyle Massie. Kim Urian, Keshav Jaganathan and Robert Sheehan provided valuable statistical advice and assistance. We thank Andy Read and Kim Urian from Duke University Marine Lab and two anonymous reviewers for insightful comments.

\section{REFERENCES}

Adams, J., Speakman, T., Zolman, E. and Schwacke, L.H. 2006. Automating image matching, cataloguing and analysis for photo-identification research. Aquat. Mamm. 32(2): 374-84.

Amstrup, S.C., McDonald, T.L. and Manly, B.F.J. (eds) 2005. Handbook of Capture-Recapture Analysis. Princeton University Press, Princeton. $336 \mathrm{pp}$.

Baillargeon, S. and Rivest, L.-P. 2007. Rcapture: Loglinear models f or capture-recapture in R. J. Stat. Softw. 19(5). [Available at: https://dx.doi.org/10.18637/jss.v019.i05]

Balmer, B.C., Wells, R.S., Nowacek, S.M., Nowacek, D.P., Schwacke, L.H., McLellan, W.A., Scharf, F.S., Rowles, T.K., Hansen, L.J., Spradlin, T.R. and Pabst, D.A. 2008. Seasonal abundance and distribution patterns of common bottlenose dolphins (Tursiops truncatus) near St. Joseph Bay, Florida, USA. J. Cetacean Res. Manage. 10(2): 157-68.

Bottlenose Dolphin Take Reduction Team (BDTRT). 2017. Key Outcomes Memorandum. Bottlenose Dolphin Take Reduction Team Webinar Meeting Wednesday, September 27, 2017. (unpublished). 9pp. [Available at: https://www.fisheries.noaa.gov/webdam/download/70844481].

Brusa, J.L., Young, R.F. and Swanson, T. 2016. Abundance, ranging patterns, and social behavior of bottlenose dolphins (Tursiops truncatus) in an Estuarine Terminus. Aquat. Mamm. 42(1): 109-21.

Burnham, K.P. and Anderson, D.R. 2002. Model Selection and Multimodel Inference: A Practical Information - Theoretic Approach. 2nd ed. Springer-Verlag, New York. 488pp.

Carrillo, J.M., Overstreet, R.M., Raga, J.A. and Aznar, F.J. 2015. Living on the Edge: Settlement Patterns by the Symbiotic Barnacle Xenobalanus globicipitis on small cetaceans. PLOS ONE 10(6): e0127367.

Cooch, E. and White, G.C. 2006. Program MARK: a gentle introduction. 652pp. [Available at: http://www.phidot.org/software/mark/docs/book/]. 
Dunn, C.N., Silva, D.C., Deborde, E.P. and Young, R.F. 2014. Distribution and movements of bottlenose dolphins (Tursiops truncatus) along the northern South Carolina coast: a research partnership with ecotourism. The Coastal Business Journal 14(1): 63-76.

Fleming, K. 2004. The social structure, behavior, and occurrence of bottlenose dolphins in relation to shrimp trawlers in Southport, North Carolina. Master's Thesis. University of North Carolina-Wilmington. 52pp. [Available at: http://libres.uncg.edu/ir/uncw/flflemingk2004-1.pdf].

Gorgone, A.M., Eguchi, T., Byrd, B.L., Altman, K.M. and Hohn, A.A. 2014. Estimating the abundance of the northern North Carolina estuarine system stock of common bottlenose dolphins (Tursiops truncatus). NOAA Tech. Mem. NMFS-SEFSC-664. 22pp. [Available at: https://dx.doi.org/ 10.7289/V5VH5KS8].

Halpin, P.N., Read, A.J., Fujioka, E., Best, B.D., Donnelly, B., Hazen, L.J., Kot, C., Urian, K., LaBrecque, E., Dimatteo, A., Cleary, J., Good, C., Crowder, L.B. and Hyrenbach, K.D. 2009. OBIS-SEAMAP: The world data center for marine mammal, sea bird, and sea turtle distributions. Oceanography 22: 104-15.

Kane, E.A., Olson, P.A., Gerrodette, T. and Fiedler, P.C. 2008. Prevalence of the commensal barnacle Xenobalanus globicipitis on cetacean species in the eastern tropical Pacific Ocean and a review of global occurrence. Fish. Bull. 106: 395-404

Lukacs, P. 2013. Closed population capture-recapture models. pp.541-78. In: Cooch, E. and White, G. (eds). Program MARK: A Gentle Introduction. EGC, New York.

Morris, S.E., Zelner, J.L., Fauquier, D.A., Rowles, T.K., Rosel, P.E., Gulland, F. and Grenfell, B.T. 2015. Partially observed epidemics in wildlife hosts: modelling an outbreak of dolphin morbillivirus in the northwestern Atlantic, June 2013-2014. J. R. Soc. Interface. 12(112): 20150676.

R Development Core Team. 2015. R: A language and environment for statistical computing. R Foundation for Statistical Computing, Vienna, Austria. [Available at: http://www.R-project.org/]

Read, A., Urian, K., Waples, D., Swaim, Z., Foley, H. and Kaufmann, R. 2013. Stock discrimination of bottlenose dolphins along the Outer Banks of North Carolina; implications for the risk of entanglement in coastal gill net fisheries. Final Report. North Carolina Sea Grant Bycatch Marine Mammal Project 10-DMM-01. 35pp. [Available from the author].

Read, A.J., Urian, K.W., Wilson, B. and Waples, D.M. 2003. Abundance of bottlenose dolphins in the bays, sounds and esturies of North Carolina. Mar. Mam. Sci. 19(1): 59-73.

Rivest, L.-P. and Baillargeon, S. 2014. Rcapture: Loglinear Models for Capture-Recapture Experiments. R package v.1.4-2. 57pp. [Available at: https://CRAN.R-project.org/package=Rcapture $]$.

Rivest, L.-P. and Lévesque, T. 2001. Improved Log-Linear model estimators of abundance in capture-recapture experiments. Can. J. Stat. 29(4): 555-

Rosel, P.E., Mullin, K.D., Garrison, L., Schwacke, L.S., Adams, J., Balmer, B., Conn, P., Conroy, M.J., Eguchi, T., Gorgone, A., Hohn, A., Mazzoil, M., Schwarz, C., Sinclair, C., Speakman, T., Urian, K., Vollmer, N., Wade, P., Wells, R. and Zolman, E. (eds) 2011. Photo-identification capturemark-recapture techniques for estimating abundance of bay, sound, and estuary populations of bottlenose dolphins along the U.S. East coast and Gulf of Mexico: a workshop report. NOAA Tech. Mem. NMFS-SEFSC621. 30pp. [Available at: https://repository.library.noaa.gov].

Rountree, R.A. and Able, K.W. 2007. Spatial and temporal habitat use patterns for salt marsh nekton: implications for ecological functions. Aquat. Ecol. 41(1): 25-45.

Seber, G.A.F. 1982. The Estimation of Animal Abundance and Related Parameters. 2nd ed. Charles Griffin and Company Ltd., London. i$\mathrm{xvii}+654 \mathrm{pp}$.
Silva, D.C. 2016. Use of photo-identification and mark-recapture techniques to identify characteristics of the stock structure of coastal bottlenose dolphins (Tursiops truncatus) off northern South Carolina. Master's thesis, Coastal Carolina University. 115pp.

Speakman, T.R., Lane, S.M., Schwacke, L.H., Fair, P.A. and Zolman, E.S. 2010. Mark-recapture estimates of seasonal abundance and survivorship for bottlenose dolphins (Tursiops truncatus) near Charleston, South Carolina, USA. J. Cetacean Res. Manage. 11(2): 153-62.

Toth-Brown, J. and Hohn, A.A. 2007. Occurrence of the barnacle, Xenobalanus globicipitis, on coastal bottlenose dolphins (Tursiops truncatus) in New Jersey. Crustaceana 80(10): 1271-79.

Toth, J.L., Hohn, A.A., Able, K.W. and Gorgone, A.M. 2012. Defining bottlenose dolphin (Tursiops truncatus) stocks based on environmental, physical, and behavioral characteristics. Mar. Mam. Sci. 28(3): 461-78.

Urian, K. 2016. MABDC bottlenose dolphin sightings. Data downloaded from OBIS-SEAMAP http://seamap.env.duke.edu/dataset/663 on 15 March 2016

Urian, K., Hohn, A.A. and Hansen, L.J. 1999. Status of the photoidentification catalog of coastal bottlenose dolphins of the western North Atlantic. Report of a workshop of catalog contributors. NOAA Tech Memo. NMFS-SEFSC 425: 22pp. [Available from: http://www.nmfs.gov]

Urian, K., Read, A., Gorgone, A., Balmer, B., Wells, R., Hammond, P., Berggren, P., Durban, J., Eguchi, T. and Rayment, W. 2015. Recommendations for photo identification methods used in capturerecapture models with cetaceans. Mar. Mamm. Sci. 31: 298-321.

Urian, K.W., Kaufmann, R., Waples, D.M. and Read, A.J. 2019. The prevalence of ectoparasitic barnacles discriminates stocks of Atlantic common bottlenose dolphins (Tursiops truncatus) at risk of entanglement in coastal gill net fisheries. Mar. Mam. Sci. 35(1): 290-99.

Urian, K.W., Waples, D.M., Tyson, R.B., Hodge, L.E.W. and Read, A.J. 2014. Abundance of bottlenose dolphins (Tursiops truncatus) in estuarine and near-shore waters of North Carolina, USA. Journal of North Carolina Academy of Science 129(4): 165-71.

Urian, K.W. and Wells, R.S. 1996. Bottlenose dolphin photo-identification workshop: March 21-22, 1996, Charleston, South Carolina. NOAA Tech. Mem. NMFS-SEFSC-393: 72pp. [Available from $h t t p: / / w w w . n m f s . n o a a$. gov/publications.htm].

Van Waerebeek, K., Reyes, J.C. and Alfaro, J. 1993. Helminth parasites and phoronts of dusky dolphins, Lagenorhynchus obscurus, (Gray, 1828) from Peru. Aquat. Mamm. 19(3): 159-69.

Wade, P.R. and Angliss, R.P. 1997. Report of the GAMMS Workshop, April 3-5, 1996, Seattle, Washington. NOAA Technical Memorandum NMFS OPR-12. [Available from: http://www.nmfs.gov].

Waring, G.T., Josephson, E., Maze-Foley, J. and Rosel, P.E. 2014. U.S. Atlantic and Gulf of Mexico Marine Mammal Stock Assessments 2013. NOAA Tech. Mem. NMFS-NE-228. 475pp. [Available at: https://repository.library.noaa.gov/view/noaa/4757].

Waring, G.T., Josephson, E., Maze-Foley, K. and Rosel, P.E. 2016. U.S. Atlantic and Gulf of Mexico Marine Mammal Stock Assessments - 2015 Report No. NMFS-NE-238. 501pp. [Available at: http://www.nmfs.noaa. gov/pr/sars/].

Williams, B.K., Nichols, J.D. and Conroy, M.J. 2002. Analysis and Management of Animal Populations. Academic Press, San Diego, CA $815 \mathrm{pp}$

Wilson, B., Hammond, P.S. and Thompson, P.M. 1999. Estimating size and assessing trends in a coastal bottlenose dolphin population. Ecol. Appl. 9: $288-300$

Würsig, B. and Jefferson, T.A. 1990. Methods of photo-identification for small cetaceans. Rep. Int. Whal. Comm (special issue) 12: 43-52.

Young, R.F. and Phillips, H.D. 2002. Primary production required to support bottlenose dolphins in a salt marsh creek system. Mar. Mam. Sci. 18(2): 358-73. 